existence of the premisses do not practically obtain. I may remark, however, that Mr. Prideaux does not show how or in what manner my arguments are inapplicable, but contents himself with pointing out what he imagines to be an error in my conception of the mechanism of the part in question. Now, I candidly confess that my knowledge of the state of things at the base of the aorta was not based upon practical observation, but at the same time I must, in justice to myself, say that in the mental review which I took of the possibilities of construction of the valves, I recognised the probable existence of the case which forms the subject of Mr. Prideaux's demonstration. But as he seems to think that if this error be granted the whole reasoning which follows is consequently invalid, I assert that it is by no means obviously certain, à priori, that an alteration in the conditions of its application must necessarily modify the conclusion. On the contrary, this very point which he deems it needless to prove because he has no doubt that it will be allowed, is the very point on which the whole question turns. I think also that in the further illustration of this I shall be able to show that Mr. Prideaux has missed the sole idea for which I was anxious to contend, viz., "that no mechanical advantage is gained by the expansion of the aorta towards its termination." Moreover, if I can point out the occasion of his difference from myself, $\mathrm{I}$ shall at the same time be rendering my own assurance the more complete.

In the first place, then, I think the difference is more verbal than real, and depends upon a certain ambiguity in the term "force of reflux." This I have interpreted to mean the pressure which would be represented by an area equal to the normal calibre of the vessel, being of opinion that it cannot naturally be applied to the multiplied pressure which would be given by taking the total area of expansion as its equivalent. The former pressure is transmitted without diminution to the unsupported area of the valves.

Again, the statement that "awing to the expansicn of the aorta towards its termination, the force of reflux is most efficiently sustained by the muscular substance of the ventricle," is undoubtcdly true in one sense; but in this case it is reduced to a mere truism, and amounts simply to this, that "the muscular substance of the ventricle being partially exposed to the contact of the column of blood, the latter rests upon it," and this, indeed, holds good whether the valves be mediate between the blood and the structure of the ventricle or not. However, I cannot help crediting the enunciation of Mr. Savory's theory with more than this, and maintain that it naturally induces the idea that the arrangement is in some way advantageous to the valves, i.e., that the pressure is lessened on the unsupported portion.

That this conclusion was contrary to mechanical laws was what I endeavoured to show in my first letter, and that my arguments are equally applicable in the present instance is evident from the fact that the existence of that portion of the valves which rests upon the ventricle is mechanically unimportant and need not be considered, since the remainder of their surface bears just the same pressure as if they were attached directly to the margin of the ventricular ring.

It is possible, however, to make one other supposition on behalf of Mr. Savory's theory, that the error lies in its statement, and not in the theory itself. If this be the case it would at any rate be much better expressed thus: "That though the aorta expands towards its termination, the increase of pressure which the valves would thus have to bear is compensated by the support which they receive from the muscular substance of the ventricle."

With regard to the last paragraph of your correspondent's letter, in which he denies the possibility of contraction of the aortic orifice during the diastole, I can only say that instead of imagining this to be the case, I expressed a strong doubt as to its occurrence. For the original statement the text-book and not myself is responsible, as may be seen from the following quotation: "The reflux of blood is most efficiently sustained by the ventricular wall, which at the moment of its occurrence is probably in a state of contraction." That this, however, should take place is, as Mr. Prideaux justly observes, an impossibility, and only proves the existence of another error either of theory or enunciation.

51, Palace Gardens Terrace

W. Percy Ashe

\section{Flight of Birds}

THE Duke of Argyll appears to maintain that a bird can remain at rest in a uniform horizontal current by simply placing and maintaining itself in a certain fixed attitude. ${ }^{*} \mathrm{He}$ seems likewise to think that the muscular effort required to maintain this attitude is somehow an explanation of the phenomenon.

But would a dead bird, of precisely the same weight, size, shape, \&c., rigidly fixed in the same attitude, also remain poised under like conditions? Of course I do not refer to the practical difficulty of maintaining an exact balance in the case of a dead bird, but in order to test the theory I suppose a mathematically uniform current and a mathematically perfect poise.

The live bird being perfectly motionless, the two would be precisely in the same mechanical condition, although the rigid attitude of the live bird would be maintained by dint of muscular exertion, and that of the dead bird by rigor mortis. Under these circumstances, would the dead bird fall to the ground or remain poised? If the former, what mechanical forces would apply to it which do not apply to the live bird? If the latter, then it would clearly follow that both birds could without change of attitude move with a uniform velocity, in a horizontal line, through still air; for it is clear that the mechanical problem is precisely the same, whether the air be in motion and the bird at rest, or the bird in motion and the air at rest. In each case the relative motion is the same.

Suppose, for example, a bird were poised at rest in a westerly breeze, moving over the earth's surface at the rate of twelve miles an hour, and suppose also the surface of the earth on account of latitude to be moving at an equal rate in the opposite direction. To anyone stationed on the surface of the earth this would be a case of the bird remaining still in a moving current. Yet, in fact, the bird would really be moving through still air at the same rate as the surface of the earth. This, I think, will be sufficient to illustrate the fact that the motionless poising of a bird in a uniform current is identical with its uniform motion through still air without change of attitude.

I need hardly point out that the muscular effort necessary to maintain the required attitude, producing no actual motion, can do no mechanical work. It cannot overcome atmospheric friction, nor the effect of the attraction of the earth.

Perhaps, indeed, the following simple way of viewing the sub ject may render it still more obvious :- -

I. If the bird were deprived of its motor weight, i.e. if it were exactly of the weight of the atmosphere, then, whatever might be its motionless attitude, it would clearly fioat a way like a balloon with the atmospheric current in which it was immersed.

2. If the air were at rest, then also under the same circumstances it must necessarily fall towards the ground, either vertically or obliquely, owing to its weight.

3. Therefore, by the most elementary law of the composition of motions, it follows that, taking into account the weight of the bird and the motion of the atmosphere, the actual resultant motion will be a motion combined of a motion vertically downwards and one or more horizontal motions.

4. The resistance of the air on the relatively still wings of the bird enables it to convert its downward motion partially into a forward motion also; but it is quite obvious that a motion combined of horizontal motions and a downward motion must result in a downward motion, and cannot produce equilibrium.

The Duke of Argyll's testimony to the fact that birds hover apparently without motion in horizontal air currents is valuable, and no doubt increases the difficulty of accounting for the phenomenon on the hypothesis of upward currents.

Graaf Reinet College

\section{F. Guthrie}

\section{To Microscopists and Entomologists}

CAN any of your readers who are microscopists and entomologists help me to a successful method of killing and mounting Hoplophora decumana-belonging to the order Acarina?

The difficulties it presents are, that on being touched it contracts its head and legs and withdraws them into the horny envelope which surrounds its body, and that portion of the envelope extending over the head then closes tightly upon the aperture, completely shutting in the head and legs, so that in this condition the creature appears like a very minute seed covered with a few spinous projections. I can find no certain method of causing it to die unclosed, or so to mount it as to exhibit its form; and as the creature is not easily met with, I shall feel much indebted by any suggestions. I may add that I have consulted experienced mounters without success.

Hill Top, Midhurst, Feb. 22

R. C. FISHER 